\title{
Unit of Sound Intensity
}

National Cancer Institute

\section{Source}

National Cancer Institute. Unit of Sound Intensity. NCI Thesaurus. Code C71330.

An indication of the type of unit of measure being used to express an acoustic power per unit area. 